\title{
International Journal of Information Sciences and Techniques (IJIST)
}

ISSN : 2249-1139 [Online]; 2319 - 409X [Print]
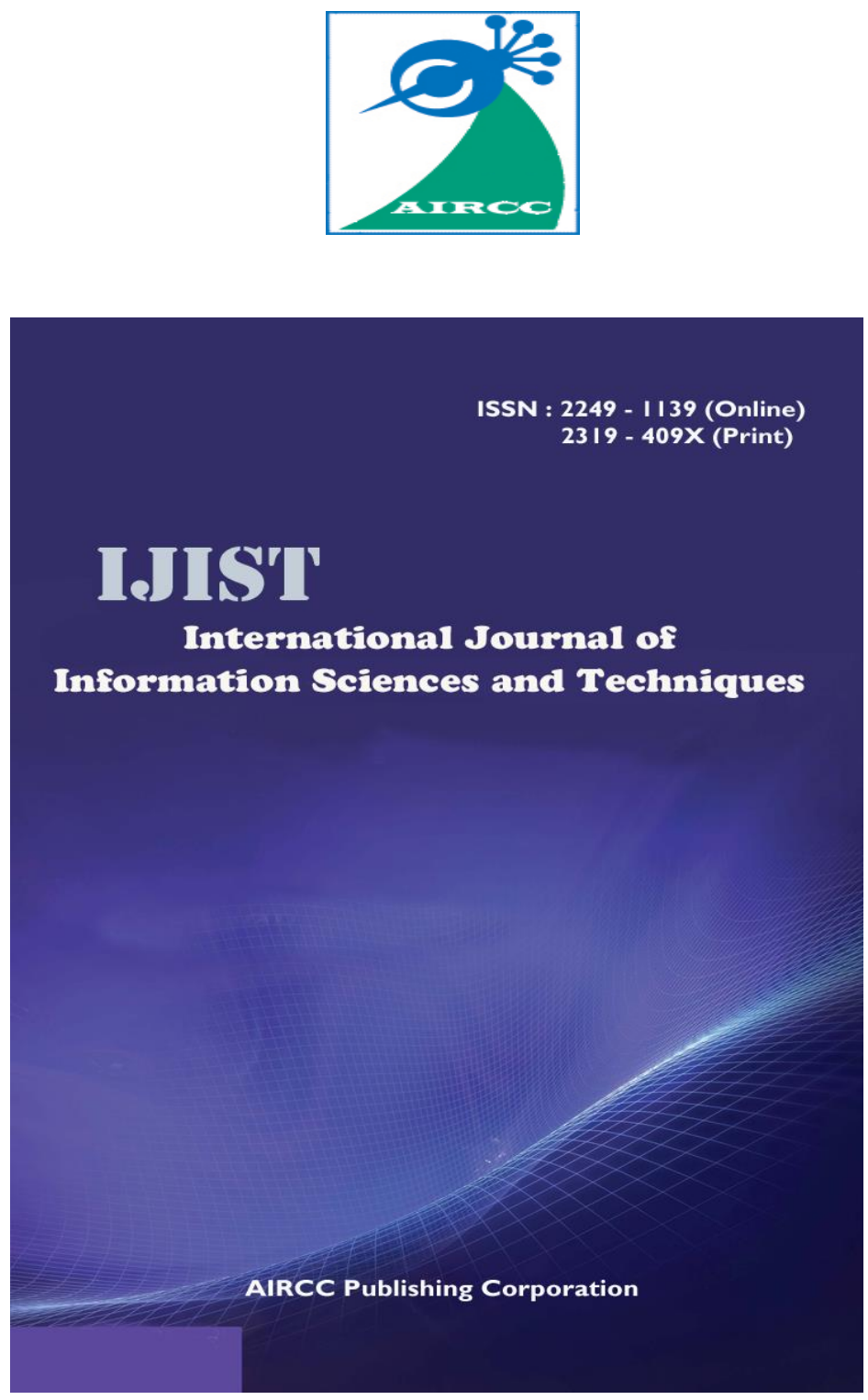

https://airccse.org/journal/IS/index.html 


\section{Scope of the Journal}

The International Journal of Information Science \& Techniques (IJIST) focuses on information systems science and technology coercing multitude applications of information systems in business administration, social science, biosciences, and humanities education, library sciences management, depiction of data and structural illustration, big data analytics, information economics in real engineering and scientific problems.

This journal provides a forum that impacts the development of engineering, education, technology management, information theories and application validation. It also acts as a path to exchange novel and innovative ideas about Information systems science and technology.

\section{Topics of interest include but are not limited to}

- $\mathrm{AI}$ and Information Science

- Archives, Preservation and Argumentation

- Business Informatics

- Community Informatics

- Computational Biology \& Bio-informatics

- Computational Social Science, Social Computing

- Cultural Informatics and Heritage

- Data Analytics, Curation and Human Centered Data

- Design and Evaluation of Information Systems and Services

- Digital Humanities, Libraries

- Diversity and Social Justice

- Economics of information systems

- Education of Information Professionals

- Ethics and Values for Information

- Fairness, accountability, transparency, ethics

- Foundations, History of Information

- Information Access, Literacy, Policy

- Information Practices and Behaviors

- Information Retrieval, Visualization

- Information Theory

- Internet Marketing

- Knowledge Representation, Ontology

- Labor Markets Online

- Libraries and Librarians

- Organization of Knowledge and Information

- Social Informatics, Media 


\section{Members of the Editorial Board}

\section{Editor In Chief}

Jan Zizka, SoNet/DI, FBE, Mendel University in Brno, Czech Republic

\section{Editorial Board Members}

- Anand Sharma ,MITS, India

- Vijayalakshmi B, Velamal College Of Management And Computer Studies, India.

- Cini Kurian ,Al-Ameen college, Kerala

- Minnie D, Madras Christian College, India

- Farheen Siddiqui,Jamia hamdard, India

- Ferdin Joe J, Prathyusha Institute of Technology \& Management, India

- Ferihane Kboubi, RIADI Lab - ENSI - University Corpus of Manouba, Tunisia

- Loshma G, Sri Vasavi Engineering College, India

- Geetha G, Anna university, India

- Hayati Mamur, Manisa Celal Bayar University, Turkey

- Issaka Hassane Abdoul-Aziz,Hunan University, China

- Japhynth J, St.Mother Theresa Engineering College, India

- Jan Zizka,SoNet/DI, FBE, Mendel University in Brno, Czech Republic.

- Chitra K,Govt Arts College for Women, India

- Kamlesh Dutta,NIT Hamirpur, India

- Khushboo Hemnani ,Trinity institute of technology and research Bhopal , India

- Krishnaveni, Avinashilingam University for Women, India

- Jaba Sheela L,Anna University, India

- Mahesh M. Goyani,Gujarat Technological University, India

- Manpreet Singh Gujral,Punjabi University, India

- Krishna Prasad M.H.M,JNTUK, India

- Mohammad Talib,University of Botswana,Botswana

- Nilesh Dhannaseth,Working with Software Company,India

- Nisar Hundewale, University of Maryland University College, USA

- Nishant Doshi,SVNIT, India

- Nitiket Nijanand Mhala, B.D.College of Engineering, Sewagram.

- Omid Pakdelazar,Iran University of Science and Technology, Iran

- Shanmugavadivu P, Gandhigram Rural Institute - Deemed University, India

- Selvarani R,MSRIT, India

- Rahul Vishwakarma, Consultancy Services, India

- Raji B,Rajshahi University, Bangladesh

- Ramgopal Kashyap, B.I.R.T.Bhopal, India

- Padma S,Vels university, India

- Sapna S, K.S.R College of Engineering, India

- Nagaraj S.V, RMK Engg College, India 


\section{Editorial Board Members}

- Sandhya Tarar,Gautam Buddha University, India

- Sanjay K ,B B Ambedkar Central University Lucknow, India

- Sanjay Singh,Manipal University, India

- Saurabh Dutta, DR. B. C. Roy Engineering College, India

- Selvaperumal, V.S.B Engineering college, India

- Shubhamoy Dey, IIM Indore, India.

- Siva Kumar A.P., JNTUniveristy Anantapur, India

- Sumit Kumar, G.L. Bajaj ,Institute of Technology \& Management, India.

- Suresh Chittineni, Anits, India

- Suresh Sankaranarayanan, Institut Teknologi Brunei, Brunei

- Tagaram Soni Madhulatha,Kakatiya University,India

- Mankar V.H,Govt. Polytechnic Nagpur, India

- Radha V, Avinashilingam University, India

- Vikas J. Government Polytechnic, India

\section{Reviewers}

- Hamid Bagheri ,Iowa State University, USA 


\section{Paper Submission \& Manuscript Preparation Guide}

Authors are invited to Submit papers for this journal through ijist@aircconline.com. Submissions must be original and should not have been published previously or be under consideration for publication while being evaluated for this Journal. For paper format download the template in this page

\section{Manuscript Template}

\section{Review Process}

Submissions are accepted for review with the understanding that the same work has been neither submitted to, nor published in, another publication. Simultaneous submission to other publications will result in immediate rejection of the paper. Papers are not within the journal scope will be rejected immediately after the pre review process.

All manuscripts will be subject to a well established, fair, unbiased peer review and refereeing procedure, and are considered on the basis of their significance, novelty and usefulness to the Journals readership. The reviewing structure will always ensure the anonymity of the referees \& it will be reviewed by 3 experts in the field. The review output will be one of the following decisions:

\section{Accept}

2. Accept with minor changes

3. Weak Accept with major changes

4. Reject

The review process may take approximately two $\sim$ three months to be completed. The Editor reserves the right to reject a paper if it does not meet the aims and scope of the journal, it is not revised well.

\section{Copy Right form}

After submitting final manuscript, you can get copy right form from AIRCC secretary

\section{Contact Us}

Here's where you can reach us: ijistjournal@yahoo.com or ijist@aircconline.com 


\section{Indexing}

Abstracting \& Indexing Services:

The Articles of IJIST are Indexed / Abstracted in the following index services

\section{getCITED

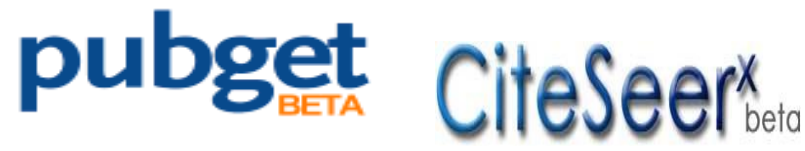

docstac

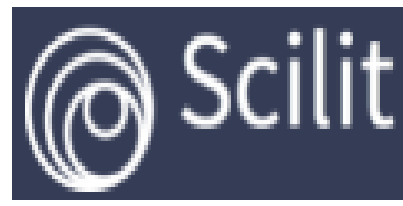

ULRICHSWEB'

GLOBAL SERALS DRECTORY

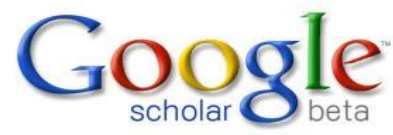

\section{Proquest}

Scribd.

Bibliographic Information

$\begin{array}{lll}\text { ISSN } & : & 2319-409 X \\ \text { e-ISSN } & : & 2249-1139 \\ \text { doi } & : & 10.5121 / \text { ijist }\end{array}$




\title{
Google Scholar Indexing
}

h-index 19, Citations 1338, i10-Index 31

\author{
More details \\ https://scholar.google.co.in/citations?user=P0AY0J0AAAAJ\&hl=en
}

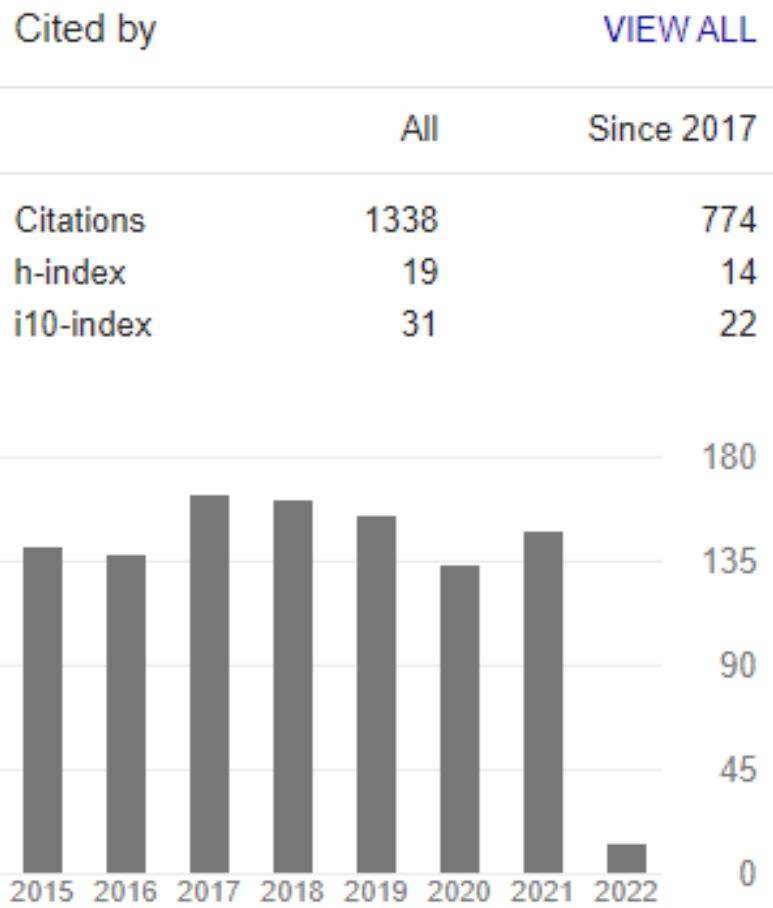

https://airccse.org/journal/IS/index.html 